\title{
Constipation induced gut microbiota dysbiosis exacerbates experimental autoimmune encephalomyelitis in C57BL/6 mice
}

Xiuli Lin ${ }^{\dagger}$, Yingying Liư ${ }^{\dagger}$, Lili Ma $^{\dagger}$, Xiaomeng Ma, Liping Shen, Xueying Ma, Zhaoyu Chen, Hao Chen, Donghong Li, Zhumin Su and Xiaohong Chen ${ }^{*}$ (i)

\begin{abstract}
Background: Constipation is a common gastrointestinal dysfunction which has a potential impact on people's immune state and their quality of life. Here we investigated the effects of constipation on experimental autoimmune encephalomyelitis (EAE), an animal model of multiple sclerosis (MS).

Methods: Constipation was induced by loperamide in female C57BL/6 mice. The alternations of gut microbiota, permeability of intestinal barrier and blood-brain barrier, and histopathology of colon were assessed after constipation induction. EAE was induced in the constipation mice. Fecal microbiota transplantation (FMT) was performed from constipation mice into microbiota-depleted mice. Clinical scores, histopathology of inflammation and demyelination, Treg/Th17 and Treg17/Teff17 imbalance both in the peripheral lymphatic organs and central nervous system, cytokines include TGF- $\beta$, GM-CSF, IL-10, IL-17A, IL-17F, IL-21, IL-22, and IL-23 in serum were assessed in different groups.

Results: Compared with the vehicle group, the constipation mice showed gut microbiota dysbiosis, colon inflammation and injury, and increased permeability of intestinal barrier and blood-brain barrier. We found that the clinical and pathological scores of the constipation EAE mice were severer than that of the EAE mice. Compared with the EAE mice, the constipation EAE mice showed reduced percentage of Treg and Treg 17 cells, increased percentage of Th17 and Teff17 cells, and decreased ratio of Treg/Th17 and Treg17/Teff17 in the spleen, inguinal lymph nodes, brain, and spinal cord. Moreover, the serum levels of TGF- $\beta$, IL-10, and IL-21 were decreased while the GM-CSF, IL-17A, IL-17F, IL-22, and IL-23 were increased in the constipation EAE mice. In addition, these pathological processes could be transferred via their gut microbiota.
\end{abstract}

Conclusions: Our results verified that constipation induced gut microbiota dysbiosis exacerbated EAE via aggravating Treg/Th17 and Treg17/Teff17 imbalance and cytokines disturbance in C57BL/6 mice.

Keywords: Constipation, Experimental autoimmune encephalomyelitis, Gut microbiota dysbiosis, Treg/Th17 and Treg17/Teff17 imbalance, Cytokine-balance disturbance

*Correspondence: chenxh5@mail.sysu.edu.cn

${ }^{\dagger}$ Xiuli Lin, Yingying Liu and Lili Ma have contributed equally to this work Department of Neurology and Multiple Sclerosis Research Center, The Third Affiliated Hospital of Sun Yat-sen University, Guangzhou, Guangdong, China

\section{Background}

Constipation is a common clinical symptom of gastrointestinal dysfunction worldwide. It is characterized by difficult or infrequent passage of stool, hardness of stool, and/or a feeling of incomplete evacuation [1,2]. Due original author(s) and the source, provide a link to the Creative Commons licence, and indicate if changes were made. The images or other third party material in this article are included in the article's Creative Commons licence, unless indicated otherwise in a credit line to the material. If material is not included in the article's Creative Commons licence and your intended use is not permitted by statutory regulation or exceeds the permitted use, you will need to obtain permission directly from the copyright holder. To view a copy of this licence, visit http://creativecommons.org/licenses/by/4.0/. The Creative Commons Public Domain Dedication waiver (http://creativeco mmons.org/publicdomain/zero/1.0/) applies to the data made available in this article, unless otherwise stated in a credit line to the data. 
to the stressful lifestyle, the prevalence of constipation is estimated to be as high as $20 \%$ in some populations including Asia [3-5]. It affects the quality of people's life among all ages and genders [3-5]. Growing evidences have indicated that constipation can lead to gut microbiota dysbiosis [1]. Gut microbiota plays an important role in regulating $\mathrm{T}$ cells differentiation and cytokines secretion. The alterations in gut microbiota have been implicated in the pathogenesis of both intestinal and non-intestinal autoimmune diseases such as ulcerative colitis and Crohn's disease, rheumatoid arthritis and multiple sclerosis (MS) [6-8].

MS is a chronic inflammatory, demyelinating, and degeneration autoimmune disease in the central nervous system (CNS) [9]. MS could be triggered by both genetic factors and environmental exposures. Its incidence rate has increased with the changed and stressful lifestyle [10]. Majority of MS patients exhibit constipation which could not be simply explained by the presence of CNS lesions, and constipation could precede the clinical symptoms of CNS in some MS patients $[11,12]$. At present, the effects of constipation on MS and the related mechanism remain unclear.

Regulatory $\mathrm{T}$ (Treg) cells and $\mathrm{T}$ helper (Th) 17 cells are two particular $\mathrm{T}$ cell subsets with plasticity playing important roles in the immunity of the intestine and CNS [13-15]. Treg cells play a fundamental role in maintaining immune homeostasis and inhibiting autoimmunity in MS/EAE by suppressing the activation of other immune cell types [13-15]. Th17 cells are thought to promote CNS autoimmunity and strongly associated with disease activity and CNS dysfunction [13, 14]. Treg cells and Th17 cells can convert into each other, and the Treg/Th17 balance is vital to the immunity of intestinal mucosal barriers and the inflammatory responses in MS [14, 16, 17]. Recent evidences have reported that Th17 cells can differentiate into either protective or pathogenic cells under the surrounding microenvironment [18]. Th17 cells that induced by interleukin (IL)- 6 and transforming growth factor $\beta$ (TGF- $\beta$ ) can convert into regulatory Th17 (Treg17) cells, which are protective cells that negatively regulate inflammation response [18]. Th17 cells that induced by IL- 6 and IL-23 are termed as the effector Th17 (Teff17) cells. They are pathogenic cells enhancing inflammation response [18]. It has been reported that Treg17/Teff17 imbalance plays an essential role in the development of pulmonary vasculitis, lupus nephritis, and glomerulonephritis $[19,20]$. As T cells abundantly reside in the intestinal lamina propria [16], it is worthy to explore whether the alteration of intestinal microbiota microenvironment that induced by constipation has the effects on the balance of Treg/Th17 and Treg17/Teff17 in experimental autoimmune encephalomyelitis (EAE), a classical model of MS.

In this study, EAE was induced in the loperamideinduced constipation mice. Fecal microbiota transplantation (FMT) was performed from constipation mice into microbiota-depleted mice to verify whether constipation relevant pathological changes could be transferred via their gut microbiota. Our results suggested that constipation induced gut microbiota dysbiosis exacerbated $\mathrm{EAE}$ through aggravating Treg/Th17 and Treg17/Teff17 imbalance and cytokines disturbance. And these pathological processes could be transferred via their gut microbiota by FMT. As constipation is one of the most important symptoms related to stressful lifestyle, this study implies the potential of lifestyle modulation in the alleviation of MS.

\section{Material and methods}

\section{Animals and regents}

Four- to five-week-old female C57BL/6 mice were obtained from the Experimental Animal Center of Guangdong (Guangzhou, China). Experiments were carried out according to the National Institutes of Health Guide for the Care and Use of Laboratory Animals (8th edition, 2011) [21] and approved by the Bioethics Committee of South China Agricultural University (Approval ID: 2018D066). Mice were allowed to acclimatize to the laboratory for 1 week prior to the study. Loperamide hydrochloride was purchased from MedChemExpress (New Jersey, USA). Amphotericin B, vancomycin hydrochloride, ampicillin, metronidazole, neomycin sulfate, $150 \%(\mathrm{w} / \mathrm{v})$ barium sulfate $\left(\mathrm{BaSO}_{4}\right)$ were purchased from Sangon Biotech (Shanghai, China). Fluorescein isothiocyanate-dextran 4000 (FITC-D4000), Evans blue (EB), and complete Freund's adjuvant (CFA) were purchased from Sigma-Aldrich (St. Louis, USA). A myelin oligodendrocyte glycoprotein (MOG) peptide ${ }_{35-55}$ (MEVGWYRSPFSRVVHLYRN GK) was synthesized by CL, Bio-Scientific Co., Ltd (Xi'an, China). Amino acid sequences were confirmed by amino acid analysis and mass spectrometry. The purity of the peptide was greater than $95 \%$. Mycobacterium tuberculosis H37RA was purchased from Difco (Detroit, MI, USA). Pertussis toxin (PTX) was purchased from List Biological Lab (Epsom, England). The TGF- $\beta$ enzyme-linked immunosorbent assay (ELISA) kits and ProcartaPlex ${ }^{\mathrm{TM}}$ multiplex immunoassay kit for granulocyte-macrophage colony-stimulating factor (GM-CSF), IL-10, IL-17A, IL-17F, IL-21, IL-22, IL-23 were purchased from Thermo Fisher Scientific (Massachusetts, USA). Anti-CD4 FITC-conjugated, anti-IL-17A PE-conjugated, anti-Foxp3 PE-Cy7-conjugated antibodies were purchased from Thermo Fisher Scientific (Massachusetts, USA). 


\section{Experimental design}

Four- to five-week-old female C57BL/6 mice were randomly allocated into three groups: (i) vehicle mice accepted saline solution treatment; (ii) constipation mice accepted loperamide treatment; and (iii) microbiota-depleted mice accepted antibiotic cocktail treatment. Freshly extruded stools were collected right after the constipation induction or microbiota depletion for fecal parameters measurement and $16 \mathrm{~S}$ rRNA sequencing analysis. FMT was performed from constipation mice into microbiota-depleted mice (FMT mice). After the experiments mentioned above, mice accepted EAE induction according to the protocol described below or phosphate-buffered saline (PBS) injection as control. The four groups were described as vehicle mice, EAE mice, constipation EAE mice, and FMT EAE mice. Every experiment was repeated three times.

\section{Induction of experimental constipation}

Loperamide hydrochloride was dissolved in the sterile saline solution to a final concentration of $2.4 \mathrm{mg} /$ $\mathrm{ml}$. Constipation was induced in mice by oral gavage at a dose of $9.6 \mathrm{mg} / \mathrm{kg}$ twice a day for 2 weeks [22]. The vehicle mice accepted equivalent saline solution by oral gavage alone.

\section{Fecal parameters measurement}

Vehicle mice and constipation mice were fed freely and observed in a single cage immediately after the constipation induction. The pellets were collected and counted every $10 \mathrm{~min}$ for $2 \mathrm{~h}$. The pellets were weight and dried at $70{ }^{\circ} \mathrm{C}$ for $24 \mathrm{~h}$ in a laboratory dry-oven. The content of fecal water was calculated according to the equation (wet weight - dry weight)/wet weight of fecal pellets $\times 100 \%$ [22]. Gastrointestinal transit was evaluated as previously described [22]. Briefly, after fasting $12 \mathrm{~h}$ with free access to water, the mice were fed with $150 \%(\mathrm{w} / \mathrm{v}) \mathrm{BaSO}_{4}$ by oral gavage. After that, the fecal pellets were monitored every $10 \mathrm{~min}$ for the presence of the first white pellet. The time when the first white pellet ejected was recorded.

\section{S rRNA gene sequencing}

Freshly extruded stools were collected right after the constipation induction or intestinal microbiota depletion for fecal parameters measurement and 16S rRNA sequencing analysis at BGI Co. (Shenzhen, China) according to our previously published study [23]. Briefly, DNA was extracted using QuickGene DNA tissue kit from Kurabo Company (Neyagawa, Japan) and next used for PCR amplification and sequencing of the V3 and V4 region of bacterial 16S rRNA genes with Illumina MiSeq technology.

Gene catalog construction, taxonomic annotation, and abundance calculation were performed according to the published study [24]. Alpha-diversity was calculated according to the indexes of observed species, Chao, Ace, Shannon, and Simpson. Partial least squares discrimination analysis (PLS-DA) was performed based on operational taxonomic units (OTU) abundance information using QIIME (Quantitative Insights into Microbial Ecology, version1.8.0). The differential microbial flora biomarkers among groups were performed using linear discriminant analysis (LDA) effect size (LEfSe) analysis [24].

\section{Transmission electron microscopy}

After the induction of constipation, the distal colon of vehicle mice and constipation mice were isolated and fixed at $4{ }^{\circ} \mathrm{C}$ in $4 \%$ glutaraldehyde $/ 4 \%$ paraformaldehyde (PFA) for transmission electron microscopy (TEM) according to the protocol [9]. Specimens were then rinsed with phosphoric acid, dehydrated with acetone, immersed, embedded in EPON812, and cut into Ultrathin sections $(60 \mathrm{~nm})$ using an ultratome. Grids were observed using Tecnai G2 Spirit TWIN TEM (FEI, Oregon USA).

\section{Assessment of the intestinal barrier and blood-brain barrier}

The FITC-D4000 test was performed to assess the intestinal barrier function [25]. Mice were given FITC-D4000 at a dose of $600 \mathrm{mg} / \mathrm{kg}$ body weight by oral gavage. Then the mice fasted with free access to water in the metabolic cages for $1 \mathrm{~h}$. After the experiment, blood from different groups were collected by cardiocentesis and heparinized, and then centrifuged at the condition: $10 \mathrm{~min}, 12,000 \mathrm{~g}$, $4{ }^{\circ} \mathrm{C}$. The collected plasm was protected from light and stored at $-80{ }^{\circ} \mathrm{C}$ immediately for the FITC-D4000 test. FITC-D4000 was diluted with plasma from untreated mice (blank) as standard (range 0.312-50 $\mu \mathrm{g} / \mathrm{ml}$ ). An amount of $100 \mu \mathrm{l}$ of plasma from different groups and standards were transferred to black 96-well microplates for analysis of FITC-D4000 concentration using SpectraMax M5 according to the guidelines of Molecular devices (Silicon valley, USA).

Blood-brain barrier (BBB) permeability was assessed with EB perfusion as previously described [26]. Mice were intravenously injected with $0.4 \% \mathrm{~EB}$ at a dose of $200 \mathrm{mg} / \mathrm{kg}$ and circulated for $30 \mathrm{~min}$. Then mice were fixed by cardiac perfusion with PBS and $4 \%(w / v)$ PFA. Brains were obtained and tissue cryo-sections were analyzed by fluorescence microscopy. 


\section{Intestinal microbiota depletion and fecal microbiota transplantation}

Microbiota-depleted mice were induced with an antibiotic cocktail consisted of amphotericin B $(0.1 \mathrm{mg} / \mathrm{ml})$, vancomycin hydrochloride $(5 \mathrm{mg} / \mathrm{ml})$, ampicillin $(10 \mathrm{mg} /$ $\mathrm{ml})$, metronidazole $(10 \mathrm{mg} / \mathrm{ml})$ and neomycin sulfate $(10 \mathrm{mg} / \mathrm{ml})$ by oral gavage at a dose of $10 \mathrm{ml} / \mathrm{kg}$ twice per day for 2 weeks [24]. FMT was performed immediately after the intestinal microbiota depletion. Fresh stools were collected from constipation mice immediately after constipation induction and homogenized with a sterile saline solution at the concentration of $5 \mathrm{mg} / \mathrm{ml}$ under anaerobic conditions (in the above of carbon dioxide ice). Supernatants were collected after 5 min standing and given to microbiota-depleted mice twice per day for 3 weeks by oral gavage (200 $\mu$ l per mouse) [24].

\section{EAE induction and assessment}

EAE was induced as previously described immediately after the fecal collection [27]. Briefly, mice immunized subcutaneously in the flanks of $200 \mu \mathrm{g} \mathrm{MOG}_{35-55}$ peptide emulsified in CFA including $500 \mu \mathrm{g}$ mycobacterium tuberculosis H37RA on day 0 and day 7. Immediately thereafter and on day 2, the mice received an intraperitoneal injection of $300 \mathrm{ng}$ PTX in $100 \mu \mathrm{l}$ PBS. Mice were scored daily and blindly by two researchers individually using a clinical scoring system ranging from 0 to 5 as follows: grade 5, death; grade 4.5, near death, moribund; grade 4 , complete paralysis of two limbs; grade 3 , complete paralysis of a single limb; grade 2.5, partial limb paralysis and ataxia; grade 2 , dysfunctional gait with limp tail and ataxia; and grade 1, dysfunctional gait with tail tonicity or limp tail [28].

\section{Histopathology}

The distal colon of vehicle mice and constipation mice were isolated for further pathological studies. On the 25st day post-immunization (p.i.) to initiate EAE, lumbar spinal cords were isolated from the EAE mice, constipation EAE mice, and FMT EAE mice for pathological studies. Mice from different groups were fixed by cardiac perfusion with $4 \%(\mathrm{w} / \mathrm{v})$ PFA, and the distal colon and the spinal cord were obtained and embedded in paraffin. Sections of the distal colon were stained with hematoxylin and eosin (HE) to reveal adrenal hyperplasia. The spinal cord samples were stained with HE and luxol fast blue (LFB) to evaluate inflammatory cell infiltration and demyelination, respectively. The severity of inflammatory cell infiltration was scored as followed: 0, no inflammatory cells; 1 , a few scattered inflammatory cells; 2 , organization of inflammatory infiltrates around blood vessels; 3 , extensive perivascular cuffing with extension into adjacent parenchyma, or parenchymal infiltration without obvious cuffing [29]. The demyelination was scored as followed: 1, traces of subpial demyelination; 2, marked subpial and perivascular demyelination; 3, confluent perivascular or subpial demyelination; 4, massive perivascular and subpial demyelination involving one half of the spinal cord with presence of cellular infiltrates into CNS parenchyma; 5 , extensive perivascular and subpial demyelination involving the whole cord section with presence of cellular infiltration into CNS parenchyma [30].

\section{Flow cytometry}

The spleen, inguinal lymph nodes (ILNs), brain, and spinal cord from different treated mice were collected for the flow cytometry analysis. CNS-infiltrating mononuclear cells and lymphocytes isolated from these tissues were isolated as described previously [31]. Cells were fixed and permeabilized [32], followed by fluorophoreconjugated intracellular cytokine-specific antibody staining and nuclear transcription factor-specific antibody staining. Samples were measured by a CytoFLEX and then analyzed by FlowJo (Tree Star, Ashland, OR).

\section{Analysis of cytokines production}

The serum from different treated mice were aseptically harvested on 25 st days p.i. and stored at $-80{ }^{\circ} \mathrm{C}$ immediately. The concentration of TGF- $\beta$ was determined by ELISA according to the guidelines of the manufacturer's protocol. The production of GM-CSF, IL-10, IL-17A, IL-17F, IL-21, IL-22, and IL-23 were measured using a ProcartaPlex ${ }^{\mathrm{TM}}$ multiplex immunoassay according to the guidelines of the manufacturer's protocol.

\section{Statistical analysis}

Data were expressed as mean \pm standard error of the mean (SEM). The statistical analysis was performed using SPSS 20.0 (SPSS, Inc., Chicago, IL, USA). Bioinformatics data were analyzed using Wilcoxon rank-sum test. Differences between clinical scores and histopathology scores were estimated by Kruskal-Wallis test. One-way ANOVA or Student's t-test was performed for the rest comparison between groups. When ANOVA showed significant differences, pair-wise comparisons between means were tested by Bonferroni post-hoc test or Dunnett's tests. Values of $p<0.05$ were considered statistically significant.

\section{Results}

\section{Constipation induced gut microbiota dysbiosis in mice}

Constipation was induced by loperamide in four- to fiveweek-old female C57BL/6 mice. The fecal parameters of the constipation mice presented less defecation pellets $(6.83 \pm 0.60$ vs. $13.33 \pm 0.76, p<0.001)$, fewer fecal water percentage $(34.21 \pm 2.64$ vs. $52.07 \pm 1.08, p<0.001)$, and 
increased gastrointestinal transit time $(371.67 \pm 14.47$ vs. $203.33 \pm 9.19, p<0.001)$ compared with vehicle mice (Fig. 1a).

Gut microbiota was analyzed by $16 \mathrm{~S}$ rRNA gene sequencing. We found that constipation mice exhibited significantly reduced abundance and diversity of gut microbiota showing as decreased observed species $(396.67 \pm 5.96$ vs. $428.50 \pm 7.46, p<0.05)$, indexes of Chao (430.16 \pm 7.77 vs. $483.61 \pm 7.27, p<0.01)$, ACE $(426.47 \pm 8.49$ vs. $473.11 \pm 5.46, p<0.01)$, Shannon $(4.00 \pm 0.03$ vs. $4.13 \pm 0.03, p<0.05)$, and increased indexes of Simpson $(0.05 \pm 0.00$ vs. $0.03 \pm 0.00, p<0.05)$ (Fig. 1b). Genus species phylogeny tree revealed the relationship between intestinal flora compositions in mice (Fig. 1c). By using PLS-DA, a distinct clustering gut microbiota composition was presented between the constipation mice and vehicle mice (Fig. 1d). In the phylum level, the relative abundance of Firmicutes was increased while the relative abundance of Bacteroidetes was decreased (that is the elevated Firmicutes/Bacteroidetes ratio, $\mathrm{F} / \mathrm{B}$ ratio) in constipation mice (Fig. 1e). In the genus level, we also observed that the Prevotella, Ruminococcus, and Turicibacter were increased while the Lactobacillus was decreased in constipation mice (Fig. 1f). LEfSe analysis was performed to identify the differential microbial biomarkers between the two groups (Fig. 1g, h). The LDA score showed that constipation greatly increased the levels of Turicibacter and Ruminococcus while decreased the levels of Lactobacillus compared to vehicle mice.

Verified by $16 \mathrm{~S}$ rRNA gene sequencing, antibiotic cocktail treatment significantly depleted the gut microbiota in microbiota-depleted mice (Additional file 1: Fig. S1).

\section{Constipation induced colon inflammation and injury, increased the permeability of intestinal barrier and BBB in mice}

HE staining and TEM were performed to evaluate the pathological changes of distal colon in constipation mice. As shown in Fig. 2a, a clear inflammatory cell infiltration with decreased amount and irregularly arranged microvilli were observed in the distal colon of constipation mice. The results in TEM were consistent with HE staining. Moreover, the structure of tight junctions was disrupted and the electron-dense materials were clearly reduced in constipation mice (Fig. $2 \mathrm{~b}$ ).

FITC-D4000 test was performed to assess the intestinal permeability. As shown in Fig. 2c, the concentration of FITC-D4000 significantly increased in constipation mice compared with the vehicle mice $(1.48 \pm 0.09$ vs. $0.79 \pm 0.03, p<0.001)$. Then we used EB perfusion to analyze the BBB permeability. Our results showed that the presence of EB dye (bright red) existed in both blood vessels and the brain parenchyma of constipation mice, while only existed in the blood vessels of vehicle mice (Fig. 2d). These findings indicated that both the intestinal barrier and BBB were damaged in constipation mice.

\section{Constipation induced gut microbiota dysbiosis aggravated the severity of EAE}

EAE was induced in constipation mice and FMT mice. The disease onset day indicated the day when an individual mouse showed the first symptom. The mean clinical score represented the average score of each mouse during the experiment. The overall disease burden of each mouse was presented as cumulative score. We found both constipation EAE mice and FMT EAE mice showed earlier onset of disease $(11.50 \pm 0.22$ vs. $14.5 \pm 0.22, p<0.01$ for constipation EAE mice; $11.50 \pm 0.22$ vs. $14.5 \pm 0.22$, $p<0.01$ for FMT EAE mice) than EAE mice (Fig. 3a). Compared to EAE mice, both constipation EAE mice and FMT EAE mice showed higher mean clinical scores $(1.65 \pm 0.04$ vs. $1.20 \pm 0.04, p<0.01$ for constipation EAE mice; $1.61 \pm 0.05$ vs. $1.20 \pm 0.04, p<0.05$ for FMT EAE mice) and cumulative score $(51.00 \pm 1.34$ vs. $37.08 \pm 1.40$, $p<0.01$ for constipation EAE mice; $49.83 \pm 1.40$ vs. $37.08 \pm 1.40, p<0.05$ for FMT EAE mice) (Fig. 3b, c).

The HE and LFB staining of lumbar spinal cord showed more inflammatory cell infiltration $(2.83 \pm 0.17$ vs. $1.67 \pm 0.21, p<0.05$ for constipation $\mathrm{EAE}$ mice; $2.83 \pm 0.17$ vs. $1.67 \pm 0.21, p<0.05$ for FMT EAE mice) and severer demyelination $(3.00 \pm 0.26$ vs. $1.67 \pm 0.21$, $p<0.01$ for constipation EAE mice; $2.83 \pm 0.17$ vs. $1.67 \pm 0.21, p<0.05$ for FMT EAE mice) in constipation EAE mice and FMT EAE mice compared to EAE mice (Fig. 3d, e).

\footnotetext{
(See figure on next page.)

Fig. 1 Constipation induced gut microbiota dysbiosis in mice. Constipation was induced by loperamide in four- to five -week-old female C57BL/6 mice. Fecal parameters including defecation frequency pellets/2 h, fecal water (\%), and gastrointestinal transit time were measured right after the induction of constipation (a). Fresh extruded stools were collected right after the constipation induction for $16 \mathrm{~s}$ rRNA sequencing analysis. The indexes of observed species, Chao, Ace, Shannon and Simpson in the vehicle mice and constipation mice (b). Genus species phylogeny tree (c). PLS-DA analysis based on OTU abundance information (d). Relative abundances of the gut microbiota at phylum level (e) and genus level (f). Cladogram using LEfSe analysis indicated the phylogenetic distribution of gut microbiota (g). LDA scores showed the significant bacterial differences between the vehicle mice and constipation mice (h). $N=6$ in each group. Data are displayed as mean \pm SEM. ${ }^{*} p<0.05,{ }^{* *} p<0.01$, *** $p<0.001$
} 
a
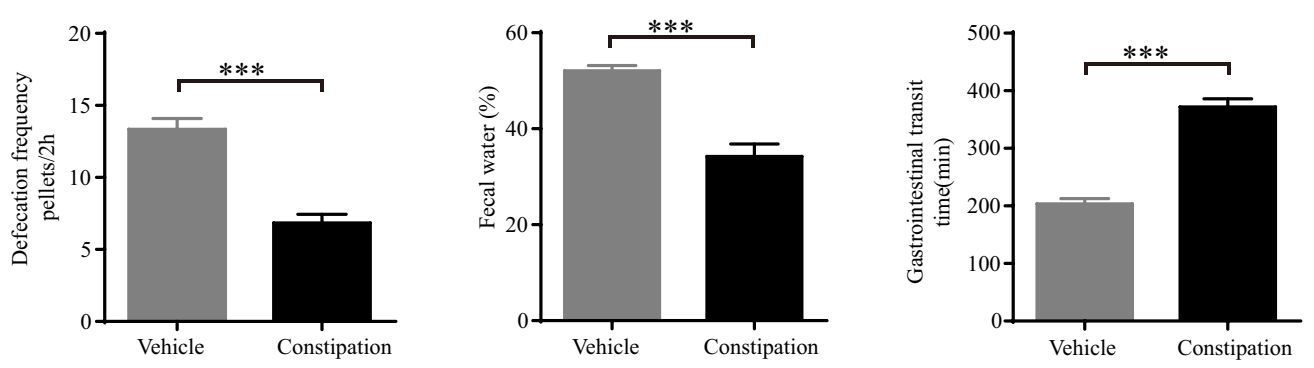

b
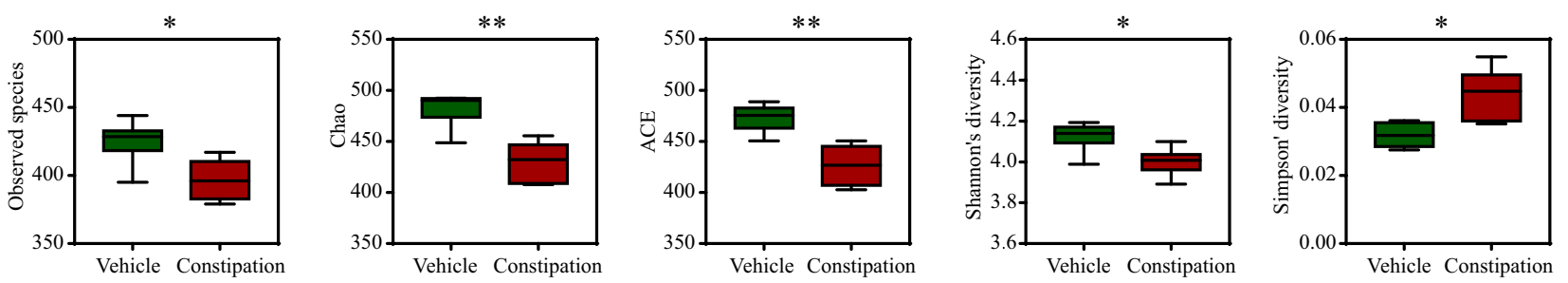

c
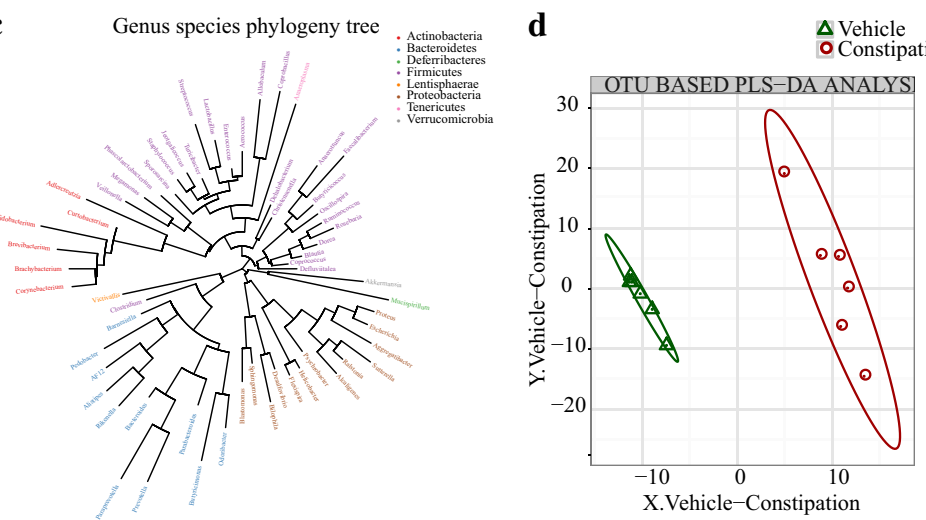

e

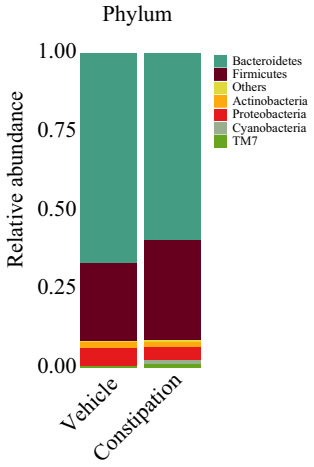

f

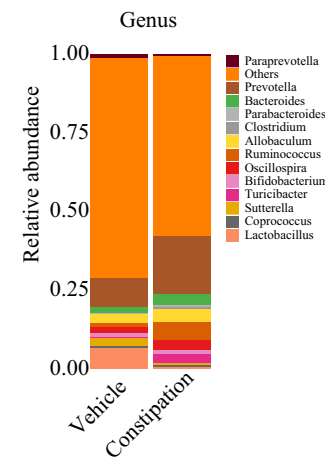

h

g Vehicle
Constipation
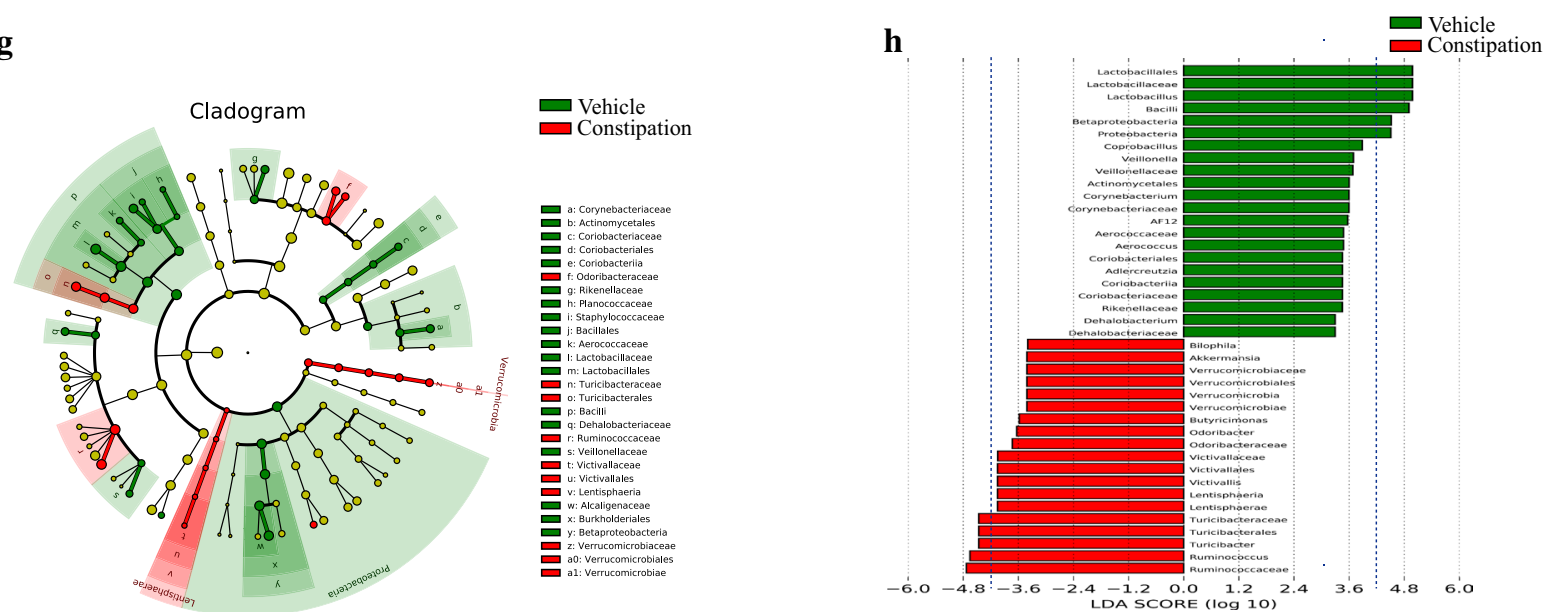

Fig. 1 (See legend on previous page.) 

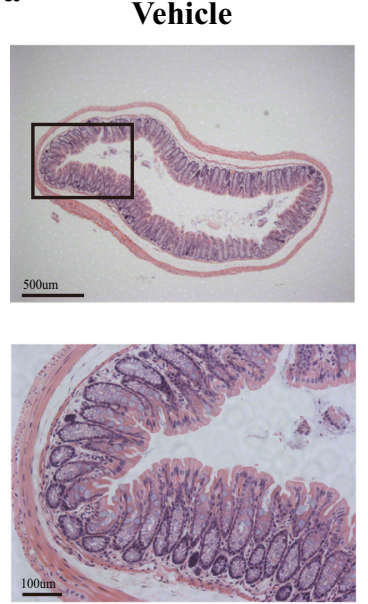

c

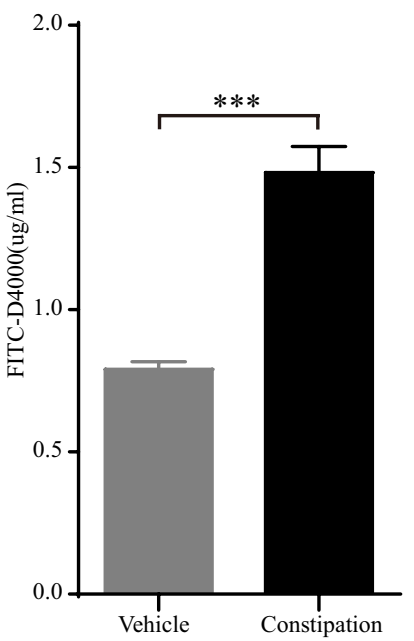

Constipation
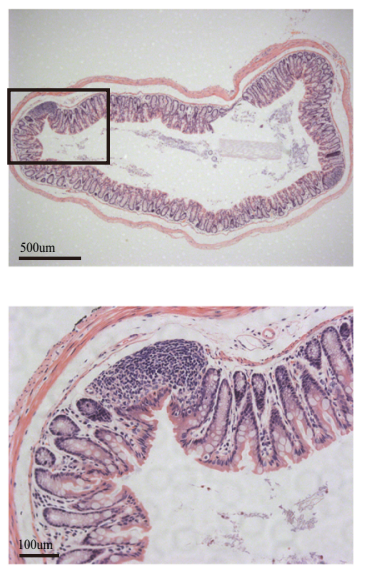

b
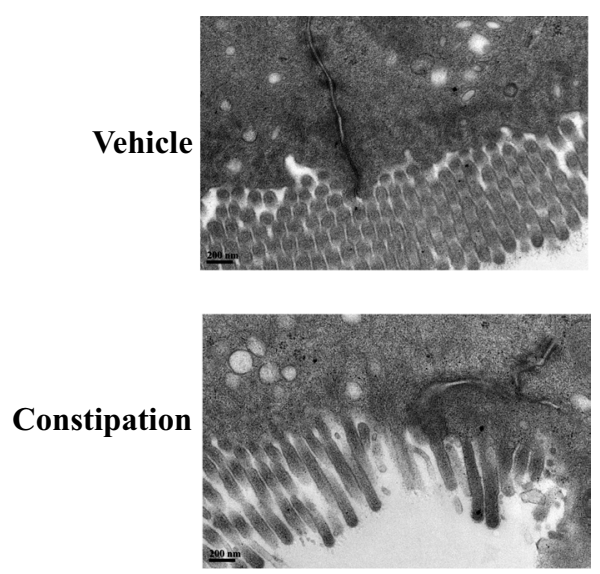

Vehicle
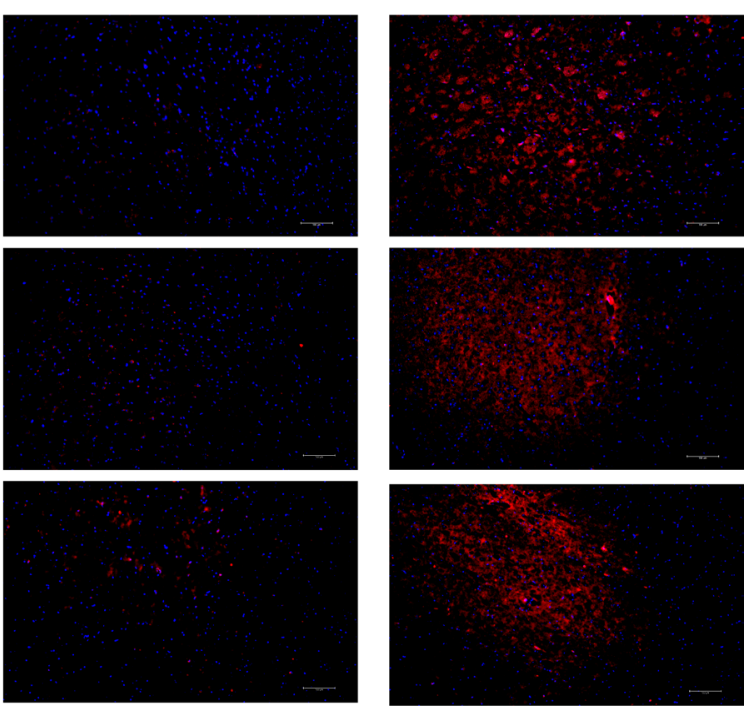

Fig. 2 Constipation induced colon inflammation and injury, increased permeability of intestinal barrier and BBB in mice. After the constipation induction, distal colon was isolated and performed HE staining $(\times 50$, scale bars $=500 \mu \mathrm{m} ; \times 200$, scale bars $=100 \mu \mathrm{m})(\mathbf{a})$ and TEM $(\times 42,000$, scale bars $=200 \mathrm{~nm})(\mathbf{b})$ for the pathological assessment. Mice were given FITC-D4000 at a dose of $600 \mathrm{mg} / \mathrm{kg}$ by oral gavage and the plasm was collected after $1 \mathrm{~h}$ to assess the intestinal permeability. The FITC-D4000 concentration in the plasm from different groups (c). Mice were intravenously injected with $0.4 \% \mathrm{~EB}$ at a dose of $200 \mathrm{mg} / \mathrm{kg}$ and circulated for $30 \mathrm{~min}$. Cortex, striatum and hippocampus were obtained and tissue cryo-sections were analyzed by fluorescence microscopy for BBB permeability assessment (d). N=6 in each group. Data are displayed as mean \pm SEM. ${ }^{*} p<0.05,{ }^{* *} p<0.01,{ }^{* * *} p<0.001$

Constipation induced gut microbiota dysbiosis aggravated Treg/Th17 and Treg17/Teff17 imbalance in EAE mice Th17 cells and Treg cells are two particular $\mathrm{T}$ cell subsets with plasticity playing important roles in the immunity of the intestine and CNS [15-17]. We further analyzed the percentage of Treg, Th17, Treg17, and Teff17 cells by flow cytometry in the EAE mice, constipation EAE mice, and FMT EAE mice. We found that the percentage of Treg and Treg17 cells were reduced, while Th17 and Teff17 cells were elevated in the spleen, ILNs, brain, and spinal cord of constipation EAE mice and FMT EAE mice. Moreover, compared with EAE mice, the Treg/Th17 and Treg17/Teff17 ratio in these tissues were lower in the constipation EAE mice and FMT EAE mice (Figs. 4, 5). 


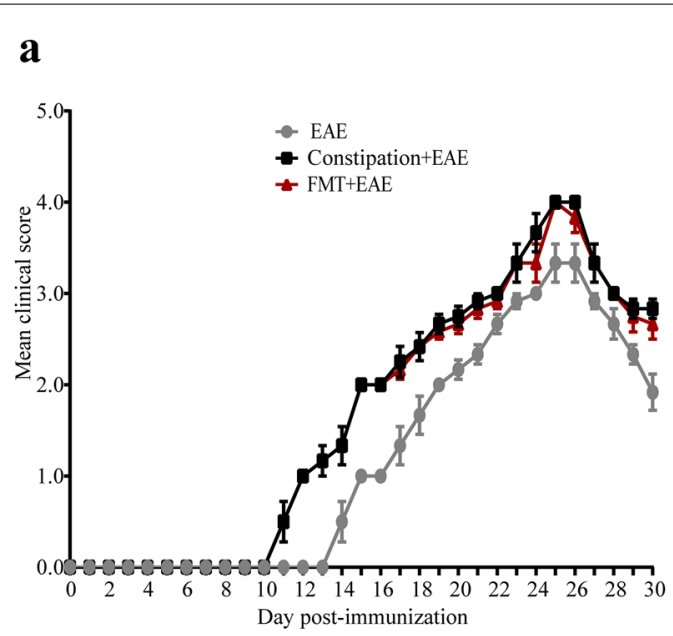

d

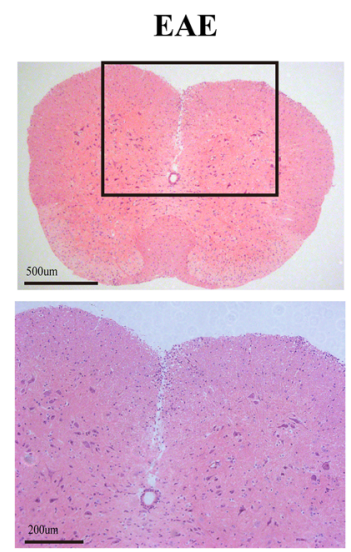

e

EAE
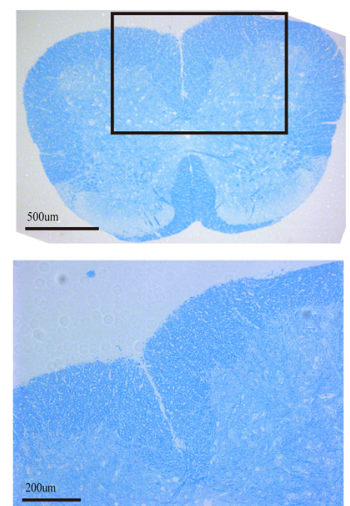

b

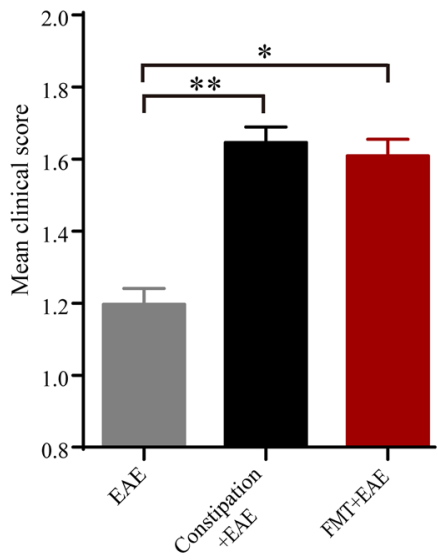

FMT+EAE
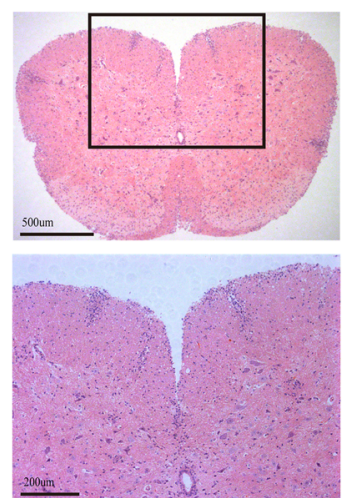

Constipation+EAE
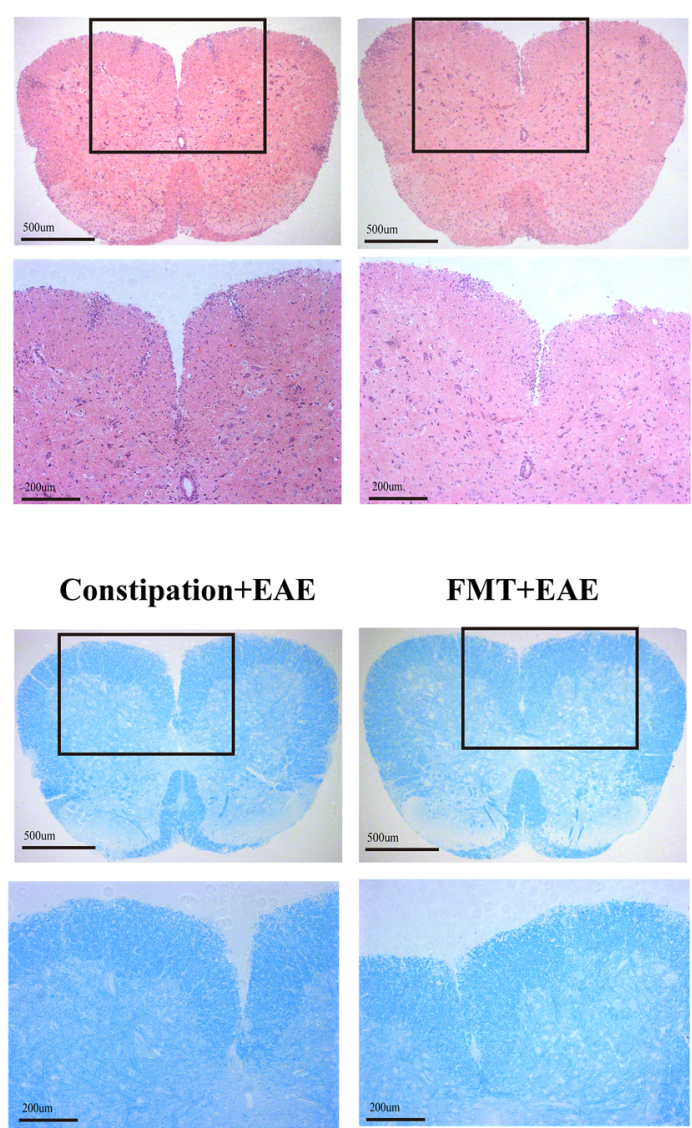

FMT+EAE
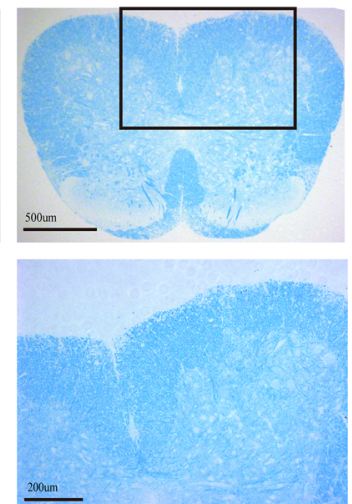

C

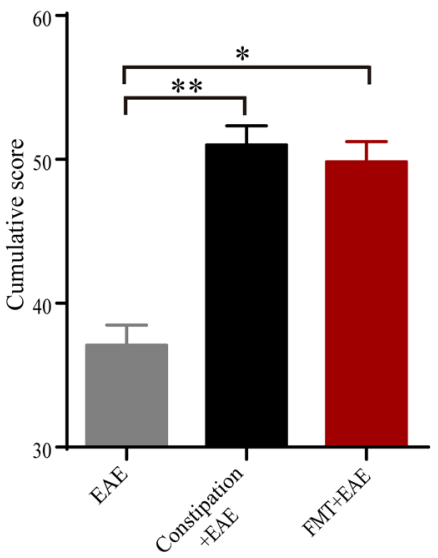

HE staining

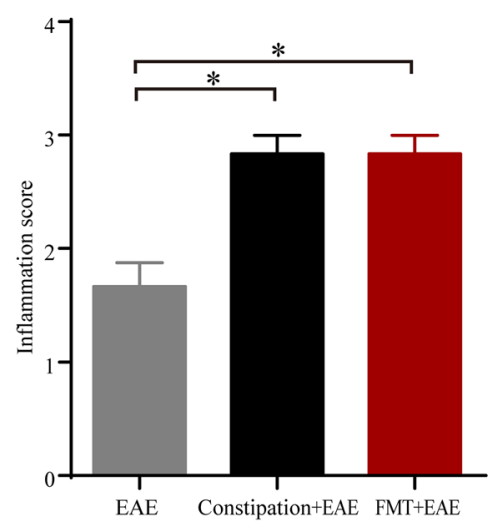

LFB staining

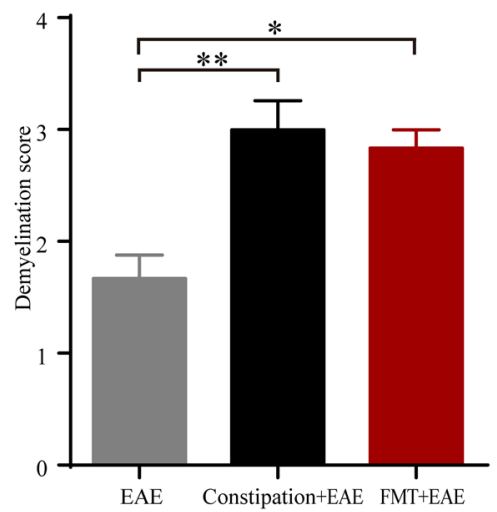

Fig. 3 Constipation induced gut microbiota dysbiosis aggravated the severity of EAE. $\mathrm{MOG}_{35-55}$ peptide was adopted for the induction of EAE in female C57BL/6 mice immediately after the fecal collection. Daily clinical scores (a), mean clinical scores (b), and cumulative scores (c) of each group mice. On the 25 st day p.i. to initiate EAE, lumbar spinal cords were isolated from the mice for pathological studies. The lumbar spinal cords were stained with HE and LFB to evaluate inflammatory cell infiltration and demyelination, respectively. Representative sections ( $\times 50$, scale bars $=500 \mu \mathrm{m} ; \times 100$, scale bars $=200 \mu \mathrm{m}$ ) and statistical analysis of the histopathological degree of the lumbar spinal cords of mice from three different groups are shown $(\mathbf{d}, \mathbf{e}) . \mathrm{N}=6$ in each group. Data are displayed as mean $\pm \mathrm{SEM} .{ }^{*} p<0.05,{ }^{* *} p<0.01,{ }^{* * *} p<0.001$ 
Constipation induced gut microbiota dysbiosis aggravated the cytokines disturbance in EAE mice

TGF- $\beta$, IL-10, and IL-21 are Treg17 cells-associated cytokines, while GM-CSF, IL-17A, IL-17F, IL-22, and IL-23 are Teff17 cells-associated cytokines [18, 33-35]. Serum was harvested at 25 st days p.i. from each group for these circulating cytokines measurement. We found that the concentrations of TGF- $\beta$, IL-10, and IL-21 were decreased while the levels of GM-CSF, IL-17A, IL-17F, IL-22, and IL-23 were increased in constipation EAE mice and FMT EAE mice compared to EAE mice (Fig. 6).

\section{Discussion}

Constipation is one of the commonest symptoms associated with stressful lifestyle [3-5]. Here, we demonstrated that constipation induced gut microbiota dysbiosis, colon injury, and increased permeability of intestinal barrier and BBB in C57BL/6 mice. In the typical animal model of MS, constipation exacerbated EAE through aggravating Treg/Th17 and Treg17/Teff17 imbalance and cytokines disturbance. And these pathological processes could be transferred via their gut microbiota.

We found that constipation mice exhibited significantly reduced abundance and diversity of gut microbiota with elevated F/B ratio in the phylum level. The increased F/B ratio have been tightly linked to the pro-inflammatory environment and immunological imbalance characteristic of autoimmune disorders [36, 37]. And it has been reported to be associated with elevated Th17 cells in the intestine and the disease activity of MS patients [38-40]. Moreover, we found that the abundance of Prevotella, Ruminococcus and Turicibacter were increased while Lactobacillus was decreased in constipation mice. Prevotella could activate Toll-like receptor 2, promoting the secretion of Th17-polarizing cytokines such as IL-23 and IL-6. Turicibacter was considered the pro-inflammatory taxa in chronic inflammatory disease [41, 42]. Ruminococcus promoted the Th17 cells differentiation and disrupted the Treg/Th17 balance, while Lactobacillus exerted opposite function [43]. We inferred that the alterations in these specific gut microbiotas may indicate the disturbed intestinal immune state in the constipation mice. And it was further verified by the increased inflammation and injury of colon that we observed in the constipation mice.

We also found that the permeability of intestinal barrier in constipation mice was increased. The intestinal barrier limits the host's contact with noxious luminal antigens, while a barrier defect has been involved in the pathogenesis of autoimmune diseases such as inflammatory bowel disease (IBD), celiac disease, irritable bowel syndrome (IBS), type 1 diabetes mellitus, and MS [4448]. Constipation induced microbiota dysbiosis can lead to the increased intestinal permeability in mice, which is supported by previous studies $[1,7]$. A dysfunctional intestinal barrier could permit microbiota driven proinflammatory state with impacts on the CNS [26], which was supported by the increased BBB permeability of the constipation mice that we observed. BBB acts as a gatekeeper in CNS, protecting the brain from exposure to antigens that may be harmful to neurons [49]. It has been reported that BBB disruption could be caused by gut microbiota dysbiosis, leading to the pathogenic antigen and serum protein leakage into CNS. This process has been previously demonstrated in the studies of schizophrenia, depression, Alzheimer's disease (AD), Parkinson's disease (PD) and MS, although the exact route is unclear [39, 47, 49-52].

Defects of the permeability of intestinal and BBB in constipation mice could influence the host immune functions, so we verified the effects of constipation on EAE mice. We found that constipation exacerbated EAE whether evaluated by clinical or pathological scores. And constipation aggravated the Treg/Th17 and Treg17/Teff17 imbalance both in the peripheral lymphoid organs and CNS in EAE mice. Treg cells and Th17 cells are two particular T cell subsets with plasticity, and their differentiations are influenced by the surrounding microenvironment [13-15]. Moreover, the Treg/ Th17 balance plays an essential role in the pathogenesis of MS and EAE [16]. Th17 cells display remarkable heterogeneity and plasticity depending on different microenvironment [13-15]. Treg17 cells are novelly defined anti-inflammatory mediator, while Teff17 cells are important pathogenic cells $[18,19]$. Moreover, the Treg17/Teff17 imbalance has been implicated in a series

(See figure on next page.)

Fig. 4 Constipation induced gut microbiota dysbiosis aggravated Treg/Th17 and Treg17/Teff17 imbalance in peripheral lymphoid organs of EAE mice. Lymphocytes were harvested from the spleens and ILNs of all mice on $25^{\text {st }}$ day p.i. and subsequently analyzed by flow cytometry. Mononuclear cells were first gated for lymphocytes followed by the gating of $\mathrm{CD} 4^{+} \mathrm{T}$ cells, and then analyzed for the percentage of Treg $\left(\mathrm{CD}^{+}\right.$Foxp $\left.^{+}\right)$cells, Th17 $\left(\mathrm{CD}^{+}{ }^{+} \mathrm{LL}-17 \mathrm{~A}^{+}\right)$cells, Treg17 $\left(\mathrm{CD} 4^{+} \mathrm{IL}-17 \mathrm{~A}^{+} \mathrm{Foxp}^{+}\right)$cells and Teff17 (CD4 ${ }^{+} \mathrm{IL}-17 \mathrm{~A}^{+}$Foxp3 $\left.{ }^{-}\right)$cells. Representative flow data showed percentage of Treg, Th17, Treg17 and Teff17 cells in the spleens and ILNs gated on CD4 positive cells of three groups (a, d). Quantification of the percentage of Treg, Th17, Treg17, Teff17 cells in the spleens and ILNs from three groups (b, e). Quantification of ratio of Treg/Th17 and Treg17/ Teff17 in the spleens and ILNs from three groups (c, $\mathbf{f}$. $N=6$ in each group. Data are displayed as mean \pm SEM. ${ }^{*} p<0.05,{ }^{* *} p<0.01,{ }^{* * *} p<0.001$ 
a

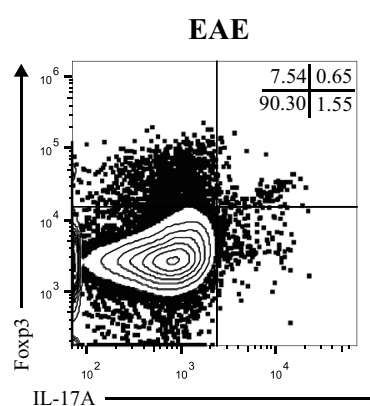

b

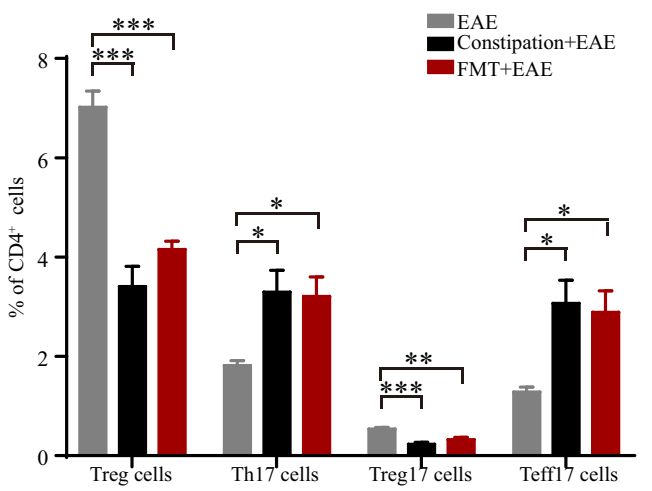

Spleen

Constipation+EAE

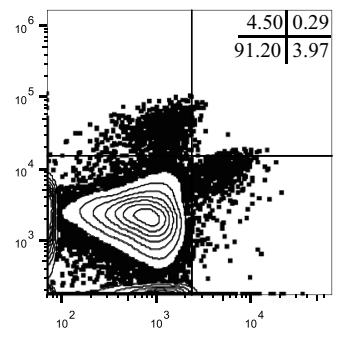

\begin{tabular}{r|r|}
4.50 & 0.29 \\
\hline 91.20 & 3.97
\end{tabular}

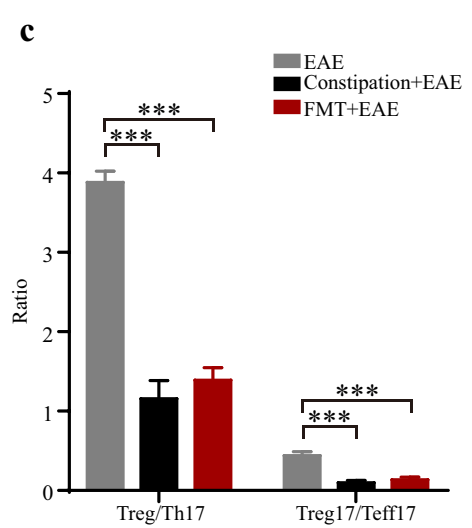

d Inguinal LNs

EAE

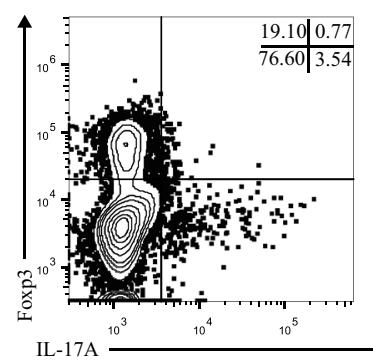

Constipation+EAE

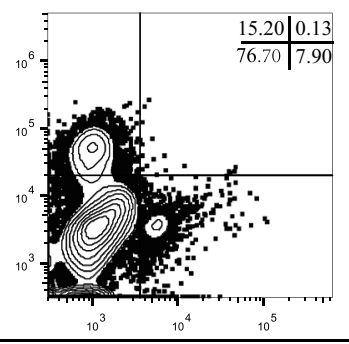

e

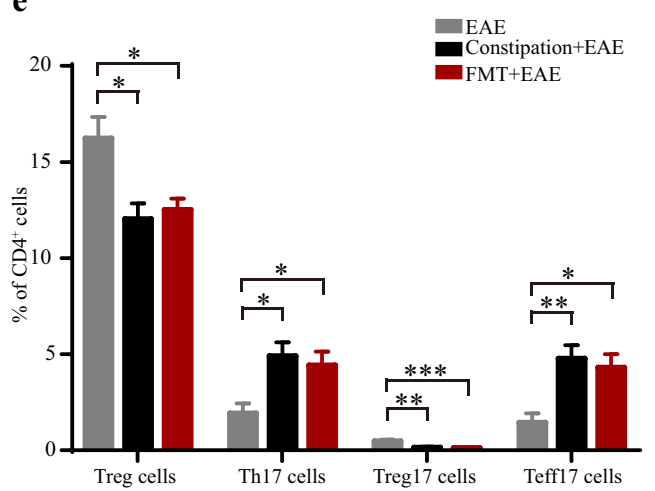

FMT+EAE

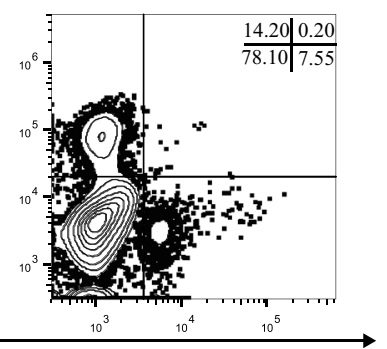

f

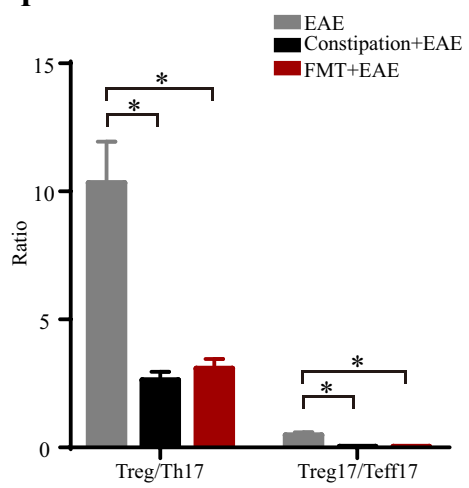

Fig. 4 (See legend on previous page.) 
of autoimmune diseases including giant cell arteritis, lupus nephritis, and glomerulonephritis, which supports that Treg17/Teff17 imbalance acts as a feature of autoimmune diseases $[19,20,53]$. Here we found the imbalance of Treg/Th17 and Treg17/Teff17 in EAE mice, and constipation aggravated the Treg/Th17 and Treg17/ Teff17 imbalance in EAE mice. As $\mathrm{T}$ cells abundantly reside in the intestinal lamina propria, constipation induced microbiota dysbiosis and the increased permeability of intestinal barrier and BBB may contribute to the increased pathological $\mathrm{T}$ cells into blood circulation and CNS then aggravated Treg/Th17 and Treg17/Teff17 imbalance in the constipation EAE mice.

Our findings are also supported by preclinical evidences that constipation induced microbiota dysbiosis could modulate brain functions by immune, endocrine and neural pathways through the brain-gut-microbiota axis in other diseases [54]. It has been reported that constipation induced microbiota dysbiosis and damaged barrier function in the pathogenesis of depression, $\mathrm{AD}$ and PD [55-57]. Although the detailed mechanistic insights of these interactions are currently underdeveloped, it is considered that constipation induced "leaky" intestinal barrier and BBB may enable the interactions among gut microbiota, immune system, and brain through multidirectional pathways [49]. FMT from the diseased animal donors to microbiota-depleted mice is the conventional manipulation for the reestablishment of gut microbial community, which could passively induce the pathological process of the diseases [58]. In this study, we found that FMT from constipation mice could exacerbate clinical severity, and Treg/Th17 and Treg17/Teff17 imbalance in EAE mice as constipation did in EAE mice. It further suggests the effects of constipation induced microbiota dysbiosis on EAE mice.

Circulation cytokines are important mediators in the communication between intestine and brain [49]. Moreover, they are well-known as the key players in the pathogenesis of MS and EAE [59]. We found the reduced levels of TGF- $\beta$, IL-10, and IL-21, and the increased levels of GM-CSF, IL-17A, IL-17F, IL-22, and IL-23 in the serum of constipation EAE mice. TGF- $\beta$, IL-10, and IL-21 were identified as typical anti-inflammatory cytokines reducing $\mathrm{T}$ cells trafficking and $\mathrm{T}$ cells responses in EAE [60, 61]. GM-CSF, IL-17A, IL-17F, IL-22 and IL-23 are Th17 cell-related cytokines, which were associated with the aggravation of immune response in EAE $[62,63]$. Th17 and Teff17 cells promote the secretions of GM-CSF, IL-17A, IL-17F and IL-22, while Treg and Treg17 cells promote the production of IL-10 and IL-21 [18]. The disturbance of circulation cytokines was consistent with the imbalance of Treg/Th17 and Treg17/Teff17 cells in the peripheral immune system and CNS in the constipation EAE mice. That whether the disturbance of circulation cytokines affected Treg/Th17 and Treg17/Teff17 cells imbalance or the imbalance of Treg/Th17 and Treg17/ Teff17 cells influenced the circulation cytokines disturbance remains unknown, but the gut dysbiosis and its influence on host barrier function may be a critical node of the changes of immune microenvironment [64]. Our results provides evidences for the assumption that the complex interplay of constipation induced microbiota dysbiosis in the changed immune microenvironment in EAE. Similarly, FMT from constipation mice in EAE could produce these effects in our study.

In summary, our study demonstrated that constipation induced gut microbiota dysbiosis and increased permeability of intestinal barrier and $\mathrm{BBB}$, which contributes to the aggravation of clinical features, the Treg/Th17 and Treg17/Teff17 imbalance, and the cytokines disturbance in EAE mice. The findings may help to further understand the effects of constipation induced gut microbiota dysbiosis in the pathogenesis of EAE. Since constipation is one of the most important stressful lifestyle related symptoms, this study implies the potential of lifestyle modulation in the alleviation of MS.

\footnotetext{
(See figure on next page.)

Fig. 5 Constipation induced gut microbiota dysbiosis aggravated Treg/Th17 and Treg17/Teff17 imbalance in CNS of EAE mice. Lymphocytes were harvested from the brains and spinal cords of all mice on $25^{\text {st }}$ day p.i. and subsequently analyzed by flow cytometry. Mononuclear cells were first gated for lymphocytes followed by the gating of $\mathrm{CD}^{+}$T cells, and then analyzed for the percentage of Treg $\left(\mathrm{CD}^{+}{ }^{+}\right.$Foxp3 $\left.{ }^{+}\right) \mathrm{cells}, \mathrm{Th}_{17}$ $\left(\mathrm{CD}^{+} \mathrm{IL}-17 \mathrm{~A}^{+}\right)$cells, Treg $17\left(\mathrm{CD}^{+} \mathrm{IL}-17 \mathrm{~A}^{+}\right.$Foxp3 $\left.^{+}\right)$cells and Teff17 (CD4 ${ }^{+} \mathrm{IL}-17 \mathrm{~A}^{+}$Foxp3 ${ }^{-}$) cells. Representative flow data showed percentage of Treg, Th17, Treg17 and Teff17 cells in the brains and spinal cords gated on CD4 positive cells of three groups (a, d). Quantification of the percentage of Treg, Th17, Treg17, Teff17 cells in the brains and spinal cords from three groups (b, e). Quantification of ratio of Treg/Th17 and Treg17/Teff17 in the brains and spinal cords from three groups $(\mathbf{c}, \mathbf{f}) . N=6$ in each group. Data are displayed as mean \pm SEM. ${ }^{*} p<0.05,{ }^{* *} p<0.01,{ }^{* * *} p<0.001$
} 
a

Brain

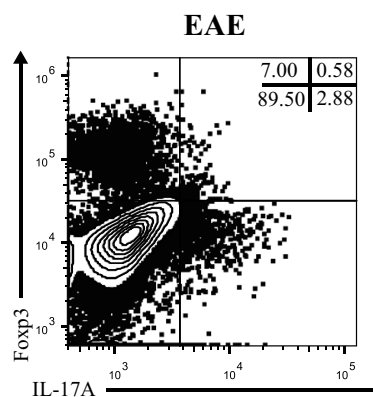

Constipation+EAE

FMT+EAE
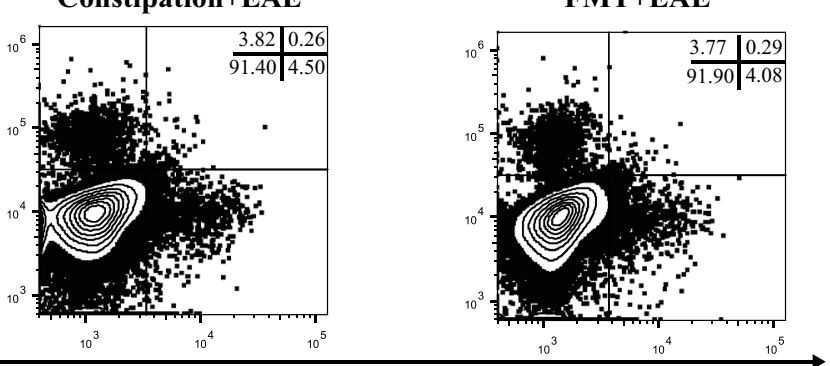

b

- Constipation+EAE
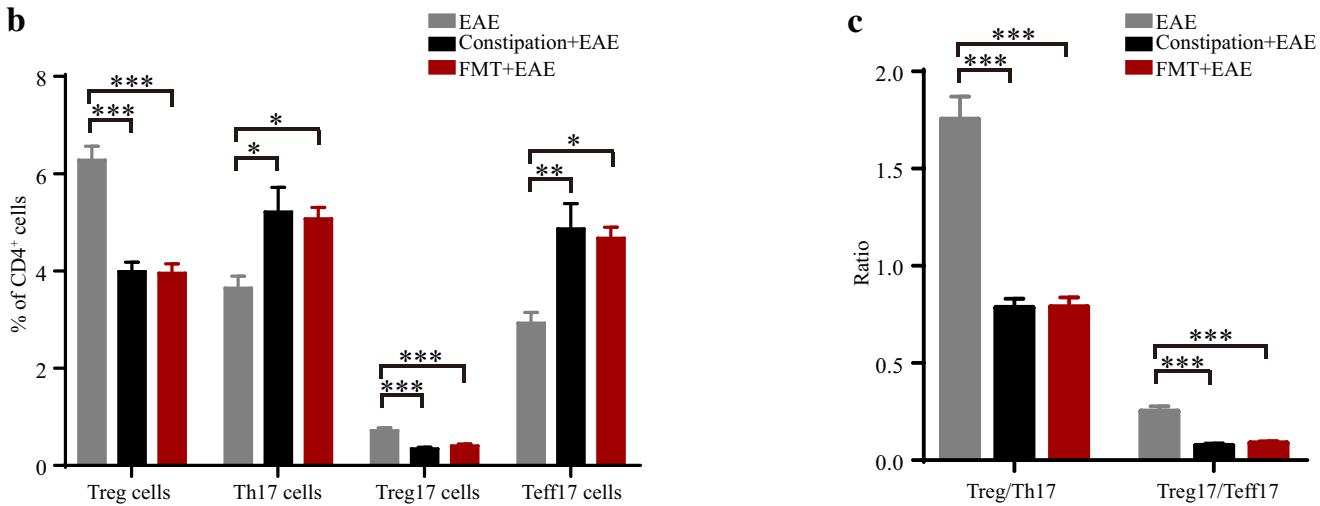

d

Spinal cord

EAE

Constipation+EAE

FMT+EAE
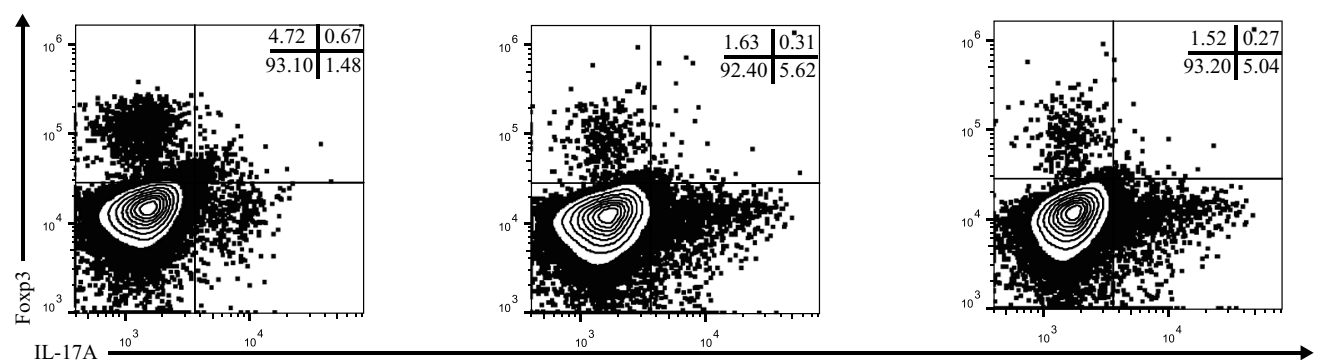

e

EAE
Constipation+EAE
FMT+EAE

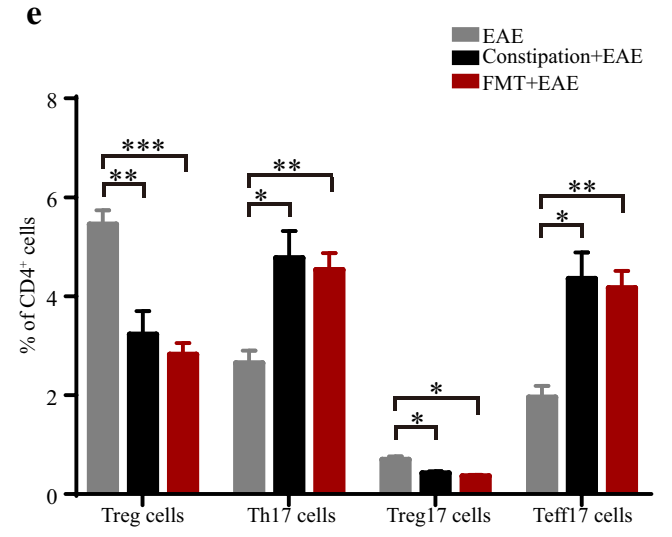

f

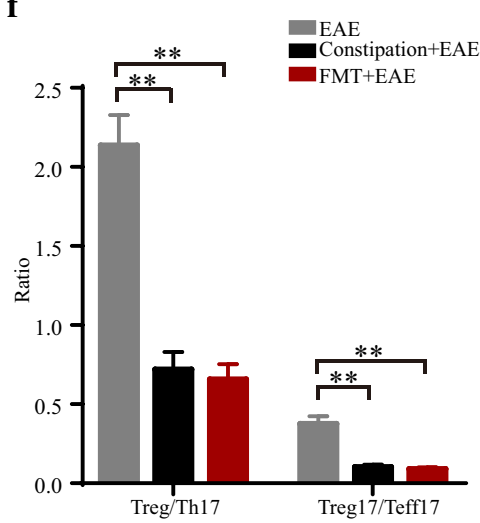

Fig. 5 (See legend on previous page.) 


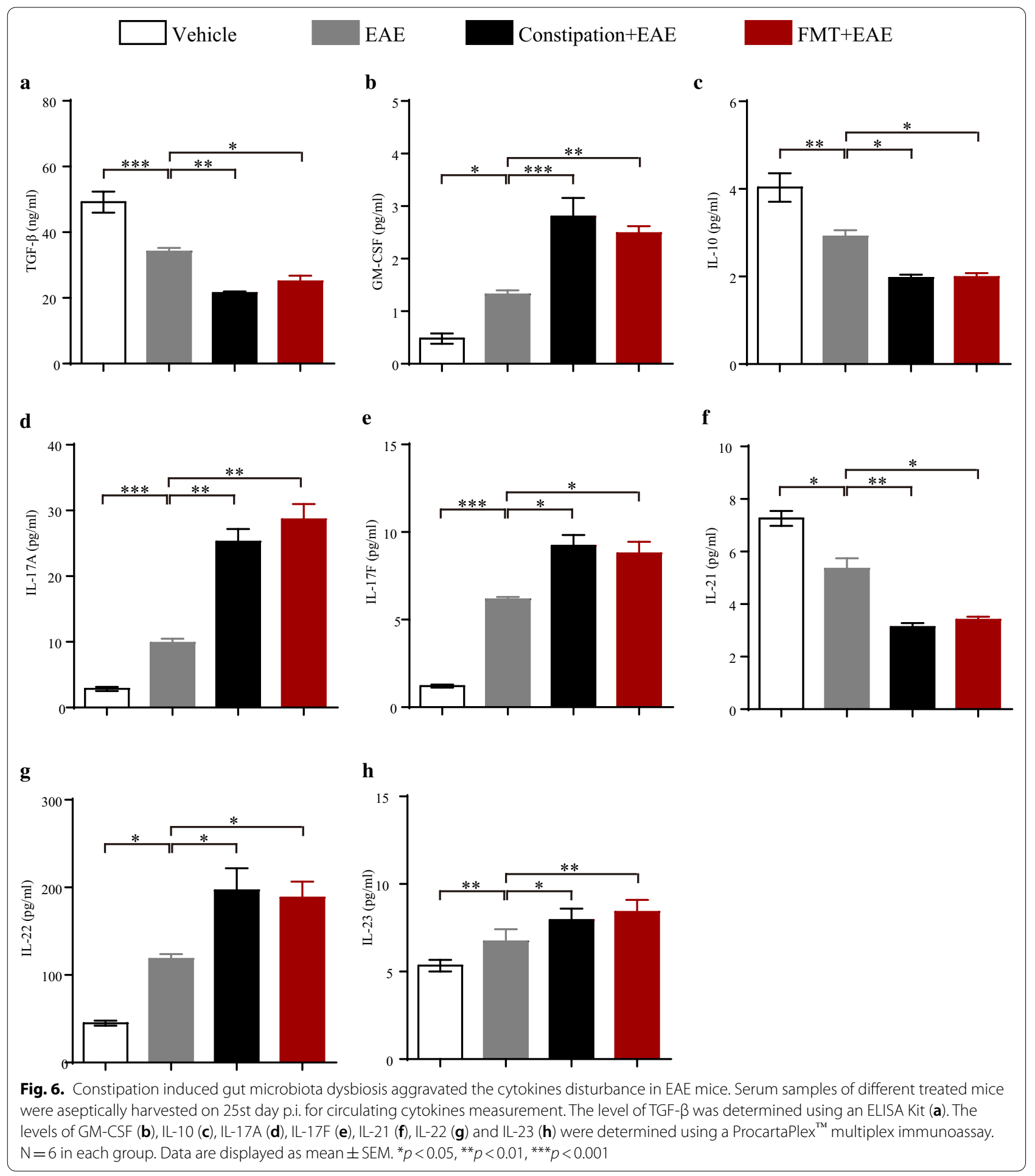




\begin{abstract}
Abbreviations
EAE: Experimental autoimmune encephalomyelitis; MS: Multiple sclerosis; FMT: Fecal microbiota transplantation; CNS: Central nervous system; Treg: Regulatory T; Th: T helper; IL: Interleukin; TGF- $\beta$ : Transforming growth factor $\beta$; Treg 17 : Regulatory Th17; Teff17: Effector Th17; $\mathrm{BaSO}_{4}$ : Barium sulfate; FITC-D4000: Fluorescein isothiocyanate-dextran 4000; EB: Evans blue; CFA: Complete Freund's adjuvant; MOG: Myelin oligodendrocyte glycoprotein; PTX: Pertussis toxin; ELISA: Enzyme-linked immunosorbent assay; GM-CSF: Granulocyte-macrophage colony-stimulating factor; PBS: Phosphate-buffered saline; PLS-DA: Partial least squares discrimination analysis; OUT: Operational taxonomic units; LEfSe: Linear discriminant analysis effect size; PFA: Paraformaldehyde; TEM: Transmission electron microscopy; BBB: Blood-brain barrier; HE: Hematoxylin and eosin; LFB: Luxol fast blue; ILNs: Inguinal lymph nodes; SEM: Standard error of the mean; F/B ratio: Firmicutes/Bacteroidetes Ratio; IBD: Inflammatory bowel disease; IBS: Irritable bowel syndrome; AD: Alzheimer's disease; PD: Parkinson's disease.
\end{abstract}

\section{Supplementary Information}

The online version contains supplementary material available at https://doi. org/10.1186/s12967-021-02995-z.

Additional file 1: Fig. S1. Antibiotic cocktail treatment significantly depleted the gut microbiota in C57BL/6 mice. Four- to five -week-old female C57BL/6 mice were administrated with antibiotic cocktail for 2 weeks. Fresh extruded stools were collected right after the antibiotic cocktail treatment for $16 \mathrm{~S}$ rRNA sequencing analysis. The indexes of observed species, Chao, Ace, Shannon and Simpson in the vehicle mice and microbiota-depleted mice (a). PLS-DA analysis based on OTU abundance information (b). Relative abundances of the gut microbiota at phylum level (c) and genus level (d). Cladogram using LEfSe analysis indicated the phylogenetic distribution of gut microbiota (e). LDA scores showed the significant bacterial differences between the vehicle mice and microbiota-depleted mice (f). $N=6$ in vehicle group, and $N=8$ in microbiota-depleted group. Data are displayed as mean \pm SEM. ${ }^{*} p<0.05$ ${ }^{* *} p<0.01,{ }^{* * *} p<0.001$

\section{Acknowledgements}

Not applicable.

\section{Authors' contributions}

Conceptualization: XHC and XLL. Investigation: XLL, YYL, LLM, XMM, LPS, $X Y M, Z Y C, H C, D H L$, and ZMS. Formal analysis: XLL, YYL and LLM. Supervision: XHC. Funding acquisition: XHC. Writing - original draft: XLL and XHC. Writing - review and editing: All authors. All authors read and approved the final manuscript.

\section{Funding}

This work was supported by Grants (to X.H.C) from the National Natural Science Foundation of China (No. 81971141), the Israel Science Foundation and the National Natural Science Foundation of China joint program (No. 813111290), the Guangdong Basic and Applied Basic Research Foundation (No. 2019A1515010201) and the Tianhe District Technology Project (2018YT019).

\section{Availability of data and materials}

The datasets used and/or analyzed during the current study are available from the corresponding author on reasonable request.

\section{Declarations}

\section{Ethics approval and consent to participate}

Experiments were carried out according to the National Institutes of Health Guide for the Care and Use of Laboratory Animals (8th edition, 2011) and approved by the Bioethics Committee of South China Agricultural University (Approval ID: 2018D066)

\section{Consent for publication}

Not applicable.

\section{Competing interests}

The authors declare that they have no competing interests.

Received: 18 April 2021 Accepted: 17 July 2021

Published online: 23 July 2021

\section{References}

1. Zhao Y, Yu YB. Intestinal microbiota and chronic constipation. Springerplus. 2016;5:1130

2. Bharucha AE. Constipation. Best Pract Res Clin Gastroenterol. 2007;21:709-31.

3. Lingu I, Kulkarni PV, Tanna I, Chandola HM. Evaluation of diet, life style and stress in the etiopathogenesis of constipation in geriatric people. Int J Res Ayurveda Pharm. 2012;3:879-83.

4. Devanarayana NM, Rajindrajith S. Association between constipation and stressful life events in a cohort of Sri Lankan children and adolescents. J Trop Pediatr. 2010;56:144-8.

5. Chadolias D, Zissimopoulos A, Nena E, Agathokleous MN, Drakopoulos $\checkmark$, Constantinidis TC, et al. Association of occupational exposures and work characteristics with the occurrence of gastrointestinal disorders. Hippokratia. 2017;21:74-9.

6. Gerritsen J, Smidt H, Rijkers GT, de Vos WM. Intestinal microbiota in human health and disease: the impact of probiotics. Genes Nutr. 2011;6:209-40.

7. Kirgizov IV, Sukhorukov AM, Dudarev VA, Istomin AA. Hemostasis in children with dysbacteriosis in chronic constipation. Clin Appl Thromb Hemost. 2001;7:335-8.

8. Fung I, Garrett JP, Shahane A, Kwan M. Do bugs control our fate? The influence of the microbiome on autoimmunity. Curr Allergy Asthma Rep. 2012:12:511-9.

9. Wunsch M, Jabari S, Voussen B, Enders M, Srinivasan S, Cossais F, et al. The enteric nervous system is a potential autoimmune target in multiple sclerosis. Acta Neuropathol. 2017;134:281-95.

10. Hosseinzadeh A, Baneshi MR, Sedighi B, Kermanchi J, Haghdoost AA. Incidence of multiple sclerosis in Iran: a nationwide, population-based study. Public Health. 2019;175:138-44.

11. Nordenbo AM, Andersen JR, Andersen JT. Disturbances of ano-rectal function in multiple sclerosis. J Neurol. 1996;243:445-51.

12. Spear ET, Holt EA, Joyce EJ, Haag MM, Mawe SM, Hennig GW, et al. Altered gastrointestinal motility involving autoantibodies in the experimental autoimmune encephalomyelitis model of multiple sclerosis. Neurogastroenterol Motil. 2018;30:e13349.

13. Kaskow BJ, Baecher-Allan C. Effector T Cells in Multiple Sclerosis. Cold Spring Harb Perspect Med. 2018;8:a029025.

14. Stadhouders R, Lubberts E, Hendriks RW. A cellular and molecular view of Thelper 17 cell plasticity in autoimmunity. J Autoimmun. 2018;87:1-15.

15. Nistala K, Adams S, Cambrook H, Ursu S, Olivito B, de Jager W, et al. Th17 plasticity in human autoimmune arthritis is driven by the inflammatory environment. Proc Natl Acad Sci USA. 2010;107:14751-6.

16. Winstead CJ. Follicular helper T cell-mediated mucosal barrier maintenance. Immunol Lett. 2014;162:39-47.

17. Bettelli E, Carrier Y, Gao W, Korn T, Strom TB, Oukka M, et al. Reciprocal developmental pathways for the generation of pathogenic effector $\mathrm{TH} 17$ and regulatory T cells. Nature. 2006:441:235-8.

18. Bellemore SM, Nikoopour E, Schwartz JA, Krougly O, Lee-Chan E, Singh B. Preventative role of interleukin-17 producing regulatory $T$ helper type 17 (Treg 17) cells in type 1 diabetes in non-obese diabetic mice. Clin Exp Immunol. 2015;182:261-9.

19. Kluger MA, Melderis S, Nosko A, Goerke B, Luig M, Meyer MC, et al. Treg17 cells are programmed by Stat3 to suppress Th17 responses in systemic lupus. Kidney Int. 2016;89:158-66. 
20. Kluger MA, Luig M, Wegscheid C, Goerke B, Paust HJ, Brix SR, et al. Stat3 programs Th17-specific regulatory T cells to control GN. J Am Soc Nephrol. 2014;25:1291-302.

21. National Research Council (US). Guide for the Care and Use of Laboratory Animals. 8th ed. National Academies Press, Washington (DC), 2011.

22. Ren X, Liu L, Gamallat Y, Zhang B, Xin Y. Enteromorpha and polysaccharides from enteromorpha ameliorate loperamide-induced constipation in mice. Biomed Pharmacother. 2017;96:1075-81.

23. Chen H, Ma X, Liu Y, Ma L, Chen Z, Lin X, et al. Gut Microbiota interventions with clostridium butyricum and norfloxacin modulate immune response in experimental autoimmune encephalomyelitis mice. Front Immunol. 2019;10:1662.

24. Cao G, Wang Q, Huang W, Tong J, Ye D, He Y, et al. Long-term consumption of caffeine-free high sucrose cola beverages aggravates the pathogenesis of EAE in mice. Cell Discov. 2017;3:17020.

25. Volynets V, Reichold A, Bárdos G, Rings A, Bleich A, Bischoff SC. Assessment of the intestinal barrier with five different permeability tests in healthy C57BL/6J and BALB/CJ mice. Dig Dis Sci. 2016;61:737-46.

26. Braniste V, Al-Asmakh M, Kowal C, Anuar F, Abbaspour A, Tóth M, et al. The gut microbiota influences blood-brain barrier permeability in mice. Sci TransI Med. 2014;6:263ra158.

27. Chen X, Hu X, Zou Y, Pi R, Liu M, Wang T, et al. Combined treatment with minocycline and prednisone attenuates experimental autoimmune encephalomyelitis in C57 BL/6 mice. J Neuroimmunol. 2009;210:22-9.

28. Xie L, Gong W, Chen J, Xie HW, Wang M, Yin XP, et al. The flavonoid kurarinone inhibits clinical progression of EAE through inhibiting Th1 and Th17 cell differentiation and proliferation. Int Immunopharmacol. 2018;62:227-36.

29. O'Neill EJ, Day MJ, Wraith DC. IL-10 is essential for disease protection following intranasal peptide administration in the C57BL/6 model of EAE. J Neuroimmunol. 2006;178:1-8

30. Kuerten S, Kostova-Bales DA, Frenzel LP, Tigno JT, Tary-Lehmann M, Angelov DN, et al. MP4- and MOG:35-55-induced EAE in C57BL/6 mice differentially targets brain, spinal cord and cerebellum. J Neuroimmunol. 2007:189:31-40

31. Cai W, Liu S, Hu M, Sun X, Qiu W, Zheng S, et al. Post-stroke DHA treatment protects against acute ischemic brain injury by skewing macrophage polarity toward the M2 phenotype. Transl Stroke Res. 2018;9:669-80.

32. Chen W, Xu Z, Zheng Y, Wang J, Qian W, Olsen N, et al. A protocol to develop Thelper and Treg cells in vivo. Cell Mol Immunol. 2017;14:1013-6.

33. McGeachy MJ, Bak-Jensen KS, Chen Y, Tato CM, Blumenschein W, McClanahan T, et al. TGF-beta and IL-6 drive the production of IL-17 and IL-10 by $T$ Cells and restrain T(H)-17 cell-mediated pathology. Nat Immunol. 2007:8:1390-7.

34. Shukla R, Ghoshal U, Ranjan P, Ghoshal UC. Expression of toll-like receptors, pro-, and anti-inflammatory cytokines in relation to gut microbiota in irritable bowel syndrome: the evidence for its micro-organic basis. J Neurogastroenterol Motil. 2018;24:628-42.

35. Xu J, Chen X, Yu S, Su Y, Zhu W. Effects of early intervention with sodium butyrate on gut microbiota and the expression of inflammatory cytokines in neonatal piglets. PLoS ONE. 2016;11:e0162461.

36. Ley RE, Turnbaugh PJ, Klein S, Gordon Jl. Microbial ecology: human gut microbes associated with obesity. Nature. 2006:444:1022-3.

37. Han L, Li T, Du M, Chang R, Zhan B, Mao X. Beneficial effects of potentilla discolor bunge water extract on inflammatory cytokines release and gut microbiota in high-fat diet and streptozotocin-induced type 2 diabetic mice. Nutrients. 2019;11:670.

38. Mestre L, Carrillo-Salinas FJ, Mecha M, Feliú A, Espejo C, Álvarez-Cermeño $\mathrm{JC}$, et al. Manipulation of gut microbiota influences immune responses, axon preservation, and motor disability in a model of progressive multiple sclerosis. Front Immunol. 2019;10:1374.

39. Cosorich I, Dalla-Costa G, Sorini C, Ferrarese R, Messina MJ, Dolpady J, et al. High frequency of intestinal TH 17 cells correlates with microbiota alterations and disease activity in multiple sclerosis. Sci Adv. 2017;3:e1700492.
40. Larsen JM. The immune response to prevotella bacteria in chronic inflammatory disease. Immunology. 2017;151:363-74.

41. Ma D, Wang AC, Parikh I, Green SJ, Hoffman JD, Chlipala G, et al. Ketogenic diet enhances neurovascular function with altered gut microbiome in young healthy mice. Sci Rep. 2018;8:6670.

42. Jeong JJ, Lee HJ, Jang SE, Han MJ, Kim DH. Lactobacillus plantarum C29 alleviates NF-kB activation and Th17/Treg imbalance in mice with TNBSinduced colitis. Food Hydrocolloids. 2018;29:1-13.

43. Kwon MS, Lim SK, Jang JY, Lee J, Park HK, Kim N, et al. Lactobacillus sakei WIKIM30 ameliorates atopic dermatitis-like skin lesions by inducing regulatory t cells and altering gut microbiota structure in mice. Front Immunol. 2018;9:1905.

44. Van Spaendonk H, Ceuleers H, Witters L, Patteet E, Joossens J, Augustyns $\mathrm{K}$, et al. Regulation of intestinal permeability: the role of proteases. World J Gastroenterol. 2017;23:2106-23.

45. Maffeis C, Martina A, Corradi M, Quarella S, Nori N, Torriani S, et al. Association between intestinal permeability and faecal microbiota composition in Italian children with beta cell autoimmunity at risk for type 1 diabetes. Diabetes Metab Res Rev. 2016;32:700-9.

46. Obrenovich MEM. Leaky gut, leaky brain? Microorganisms. 2018;6:107.

47. Proia P, Schiera G, Salemi G, Ragonese P, Savettieri G, Di Liegro I. Neuronal and BBB damage induced by sera from patients with secondary progressive multiple sclerosis. Int J Mol Med. 2009;24:743-7. https://doi.org/10. 3892/ijmm_00000287.

48. Pastorelli L, De Salvo C, Mercado JR, Vecchi M, Pizarro TT. Central role of the gut epithelial barrier in the pathogenesis of chronic intestinal inflammation: lessons learned from animal models and human genetics. Front Immunol. 2013;4:280.

49. Logsdon AF, Erickson MA, Rhea EM, Salameh TS, Banks WA. Gut reactions: How the blood-brain barrier connects the microbiome and the brain. Exp Biol Med (Maywood). 2018:243:159-65.

50. Klingelhoefer $\mathrm{L}$, Reichmann H. Pathogenesis of Parkinson disease-the gut-brain axis and environmental factors. Nat Rev Neurol. 2015;11:625-36.

51. Pistollato F, Sumalla Cano S, Elio I, Masias Vergara M, Giampieri F, Battino M. Role of gut microbiota and nutrients in amyloid formation and pathogenesis of Alzheimer disease. Nutr Rev. 2016;74:624-34.

52. Dinan TG, Cryan JF. Brain-gut-microbiota axis and mental health. Psychosom Med. 2017;79:920-6.

53. Samson M, Audia S, Janikashvili N, Bonnotte B, et al. Are IL-10+ regulatory Th17 cells implicated in the sustained response to glucocorticoid treatment in patients with giant cell arteritis? Comment on the paper of Espigol-Frigole et al. Ann Rheum Dis. 2013;72:e3.

54. Kong G, Ellul S, Narayana VK, Kanojia K, Ha HTT, Li S, et al. An integrated metagenomics and metabolomics approach implicates the microbiotagut-brain axis in the pathogenesis of Huntington's disease. Neurobiol Dis. 2021;148:105199

55. Kowalski K, Mulak A. Brain-gut-microbiota axis in Alzheimer's disease. J Neurogastroenterol Motil. 2019;25:48-60.

56. Mulak A, Bonaz B. Brain-gut-microbiota axis in Parkinson's disease. World J Gastroenterol. 2015;21:10609-20.

57. Ganci M, Suleyman E, Butt H, Ball M. The role of the brain-gut-microbiota axis in psychology: The importance of considering gut microbiota in the development, perpetuation, and treatment of psychological disorders. Brain Behav. 2019;9:e01408.

58. Zhang F, Cui B, He X, Nie Y, Wu K, Fan D, et al. Microbiota transplantation: concept, methodology and strategy for its modernization. Protein Cell. 2018;9:462-73.

59. Dendrou CA, Fugger L, Friese MA. Immunopathology of multiple sclerosis. Nat Rev Immunol. 2015;15:545-58.

60. Huss DJ, Winger RC, Cox GM, Guerau-de-Arellano M, Yang Y, Racke MK, et al. TGF- $\beta$ signaling via Smad4 drives IL-10 production in effector Th1 cells and reduces T-cell trafficking in EAE. Eur J Immunol. 2011:41:2987-96.

61. Ghalamfarsa G, Mahmoudi M, Mohammadnia-Afrouzi M, Yazdani Y, Anvari E, Hadinia A, et al. IL-21 and IL-21 receptor in the immunopathogenesis of multiple sclerosis. J Immunotoxicol. 2016;13:274-85. 
62. Uyttenhove C, Gaignage M, Donckers D, Nasr Z, Cheou P, van Snick J, et al. Prophylactic treatment against GM-CSF, but not IL-17, abolishes relapses in a chronic murine model of multiple sclerosis. Eur J Immunol. 2018:48:1883-91.

63. Qu N, Xu M, Mizoguchi I, Furusawa J, Kaneko K, Watanabe K, et al. Pivotal roles of T-helper 17-related cytokines, IL-17, IL-22, and IL-23, in inflammatory diseases. Clin Dev Immunol. 2013;2013:968549.

64. Li XJ, You XY, Wang CY, Li XL, Sheng YY, Zhuang PW, et al. Bidirectional Brain-gut-microbiota axis in increased intestinal permeability induced by central nervous system injury. CNS Neurosci Ther. 2020;26:783-90.

\section{Publisher's Note}

Springer Nature remains neutral with regard to jurisdictional claims in published maps and institutional affiliations.
Ready to submit your research? Choose BMC and benefit from:

- fast, convenient online submission

- thorough peer review by experienced researchers in your field

- rapid publication on acceptance

- support for research data, including large and complex data types

- gold Open Access which fosters wider collaboration and increased citations

- maximum visibility for your research: over 100M website views per year

At BMC, research is always in progress.

Learn more biomedcentral.com/submissions 